\title{
Long-term survival rates of gravity-assisted, adjustable differential pressure valves in infants with hydrocephalus
}

\author{
*Anna-Felicitas Gebert, Matthias Schulz, Dr med, Karin Schwarz, Dr med, and \\ Ulrich-Wilhelm Thomale, PD, Dr med \\ Pediatric Neurosurgery, Charité - Universitätsmedizin, Berlin, Germany
}

OBJECTIVE The use of adjustable differential pressure valves with gravity-assisted units in shunt therapy of children with hydrocephalus was reported to be feasible and promising as a way to avoid chronic overdrainage. In this singlecenter study, the authors' experiences in infants, who have higher rates of shunt complications, are presented.

METHODS All data were collected from a cohort of infants ( 93 patients [ 37 girls and 56 boys], less than 1 year of age [mean age $4.1 \pm 3.1$ months]) who received their first adjustable pressure hydrocephalus shunt as either a primary or secondary implant between May 2007 and April 2012. Rates of valve and shunt failure were recorded for a total of 85 months until the end of the observation period in May 2014.

RESULTS During a follow-up of $54.2 \pm 15.9$ months (range $26-85$ months), the Kaplan-Meier rate of shunt survival was $69.2 \%$ at 1 year and $34.1 \%$ at 85 months; the Kaplan-Meier rate of valve survival was $77.8 \%$ at 1 year and $56 \%$ at 85 months. Survival rates of the shunt were significantly inferior if the patients had previous shunt surgery. During follow-up, 44 valves were exchanged in cases of infection $(n=19)$, occlusion $(n=14)$, dysfunction of the adjustment unit $(n=10)$, or to change the gravitational unit $(n=1)$.

CONCLUSIONS Although a higher shunt complication rate is observed in infant populations compared with older children, reasonable survival rates demonstrate the feasibility of using this sophisticated valve technology. The gravitational unit of this valve is well tolerated and its adjustability offers the flexible application of opening pressure in an unpredictable cohort of patients. This may adequately address overdrainage-related complications from early in treatment.

http://thejns.org/doi/abs/10.3171/2015.10.PEDS15328

KEY WORDS adjustable gravitational valve; infant; hydrocephalus; shunt survival; valve survival

$\mathrm{T}$ He treatment of childhood hydrocephalus represents a relevant share of pediatric neurosurgery. Various techniques to balance the disturbed CSF dynamics are described, such as endoscopic fenestration for establishing intracranial CSF communication, transient CSF drainages by reservoirs or external drainages, CSF diversion by shunting, or the combination of CSF diversion and endoscopic fenestration. . $, 6,15,17,27,49,51$ The debate about the optimal therapy for infants with hydrocephalus continues, because they represent a challenging cohort of patients with high complication rates. Primary treatment and possible complications have a relevant impact on the long-term outcome in these patients, whose brains are still developing.
The most common complications in shunt therapy of pediatric hydrocephalus are infections, shunt occlusion, under- and overdrainage, or malpositioning of implants. In particular, overdrainage is relevant in children as a longterm complication that might lead to microcephaly, slit ventricle syndrome, hyperostosis, and chronic headaches. ${ }^{1,5,9}$, $11,14,16,31,37,38,40,41,47$ Differing valve designs, including either adjustment units or antisiphon devices, have addressed this problem and have been investigated over the years. ${ }^{2,19}$, 22,23,25,31,39,43,44,46,52-54 The adjustable differential pressure (DP) valves attempt to adjust the resistance of CSF drainage according to the individual circumstances of anatomy, activity, and CSF imbalance. So-called antisiphon devices address posture-dependent overdrainage, which

ABBREVIATIONS DP $=$ differential pressure.

SUBMITTED May 27, 2015. ACCEPTED October 7, 2015.

INCLUDE WHEN CITING Published online January 22, 2016; DOI: 10.3171/2015.10.PEDS15328.

* Ms. Gebert and Dr. Schulz contributed equally to this work. 
results from the hydrostatic forces in the standing position when the CSF drains from the elevated level of the intracranial compartment toward the lower level of the peritoneum. ${ }^{13,19,21,46} \mathrm{We}$ previously reported on the use of an adjustable DP valve with gravitational assistance, the proGAV (MIETHKE, B. Braun, Aesculap), and were able to show the feasibility of this device for the treatment of childhood hydrocephalus, as well as its acceptance by patients and caretakers. ${ }^{18,48}$

The treatment of hydrocephalus in infants is especially challenging due to their less developed immune status, delicate skin condition, rapidly changing cerebral dimensions, closure of the fontanelle and cranial sutures, and the wide range of intracranial and intraabdominal pressure conditions being influenced (e.g., by crying and abdominal pressure). Only a few studies have addressed treatment for hydrocephalus exclusively in an infant population. ${ }^{23,31,32,42,53}$ Thus, it seems reasonable to present our long-term experience in infants with hydrocephalus treated with CSF-diverting shunts using the proGAV adjustable, gravity-assisted valve, which has been routinely used at our institution since 2007.

\section{Methods}

This single-center, retrospective study included 93 patients less than 12 months old, who received a CSFdiverting shunt including an adjustable DP valve with a gravitational unit (proGAV) for the treatment of hydrocephalus. All proGAV systems (either primary implants or secondary implants used at shunt revision between May 2007 and April 2012) were identified and followed for an additional 2 years until the end of the observation period in May 2014, for a maximum of 85 months.

In the present study, the overall proGAV survival and shunt survival rates were compared after 12 months and at the end of the observation period (a maximum of 85 months). An adverse event (i.e., failure) was considered any event leading to a surgical revision of the shunt system, including infection. The infection rate was calculated as the number of documented infections divided by the number of surgeries of the whole patient cohort during the observation period. Data were retrospectively collected by a review of the operative database and the patient's medical records.

\section{ProGAV System}

The programmable gravity-assisted valve combines an adjustable DP valve with a gravitational unit, connected by silicon tubing. The adjustment unit operates by a ballin-cone mechanism, which can be magnetically changed by adjusting the position of a rotor, which in turn alters the tension of a spring toward the ball. To readjust the DP valve, a magnetic pen is used to apply pressure in the center of the unit to loosen the locking mechanism and magnetically transmit the selected setting. An opening pressure between 0 and $20 \mathrm{~cm} \mathrm{H}_{2} \mathrm{O}$ can be chosen, which represents the permanent resistance level independent of the patient's position. The gravitational unit gradually adds further resistance, which is defined by the weight of a tantalum ball, when the valve is erected from $0^{\circ}$ to a $90^{\circ}$ upright position. The gravitational unit cannot be adjusted after implantation; a unit with a resistance of $20 \mathrm{~cm} \mathrm{H}_{2} \mathrm{O}$ was always used for infants at our institution. The setting of the adjustable DP unit depends on the individual surgeon's decision in every case but was set initially between 5 and $8 \mathrm{~cm} \mathrm{H}_{2} \mathrm{O}$, according to our hospital's guidelines. The ventricular catheter was placed in a frontal precoronal position in all patients to allow the valve to be placed in a strictly vertical position subcutaneously behind the ear. ${ }^{43}$ The ventricular catheter was connected to a bur hole reservoir. Antibiotic-impregnated silicon tubes (Bactiseal; Johnson \& Johnson) were used for all cases from 2009 on, and the tubes were fixated with nonresorbable ligatures. The peritoneal catheter was inserted, with a minimum length of $35 \mathrm{~cm}$.

Readjustments of the valve setting were performed in cases of clinical symptoms or radiological signs of over- or underdrainage. An elevated setting of the valve (by $2 \mathrm{~cm}$ $\mathrm{H}_{2} \mathrm{O}$ above the normal routine resistance setting) was chosen for patients with intensive crying or activity, according to our hospital's standard protocol. Patients were seen for clinical evaluation 4-8 weeks after discharge and then every 3 months. Follow-up with MRI was arranged every 12 months and, for complex cases, 3 months after surgery.

\section{Statistical Analysis}

The software used for graph design and statistical analysis was GraphPad Prism 6 (GraphPad Software, Inc.). All values are given as the mean $\pm \mathrm{SD}$. Comparison of Kaplan-Meier survival curves was performed using the log-rank (Mantel-Cox) test. A p value less than 0.05 was considered statistically significant.

\section{Results}

The gestationally corrected mean age of the 93 patients ( 37 girls and 56 boys) at the time of shunt insertion was 4.1 \pm 3.1 months (Table 1). One girl who was born extremely prematurely (at 24 weeks of gestation) died from multiple organ failure 1 month after implantation of the valve and was therefore excluded from follow-up. The mean followup was $54.2 \pm 15.9$ months. Among the 93 patients, 46 were preterm infants (less than 37 weeks of gestation). The etiology of hydrocephalus was posthemorrhagic $(\mathrm{n}=$ $43)$, myelomeningocele $(n=18)$, idiopathic $(n=9)$, tumor

TABLE 1. Demographic data from 93 infants who received a primary or secondary proGAV implant

\begin{tabular}{ll}
\hline \multicolumn{1}{c}{ Variable } & \multicolumn{1}{c}{ Value } \\
\hline Time period of implantation & May 2007 to April 2012 \\
\hline No. of proGAV implants & 117 \\
\hline $\begin{array}{l}\text { No. of pts } \\
\begin{array}{l}\text { Mean age, mos (gestationally corrected for } \\
\text { premature infants) }\end{array}\end{array}$ & $4.1 \pm 3.1$ \\
\hline $\begin{array}{l}\text { Mean follow-up, mos (range) } \\
\text { No. of primary implants }\end{array}$ & $54.2 \pm 15.9(26-85)$ \\
\hline $\begin{array}{l}\text { No. of secondary implants (revisions) } \\
\text { neal shunts) }\end{array}$ \\
\hline
\end{tabular}


$(\mathrm{n}=5)$, postinfectious $(\mathrm{n}=5)$, complex malformations ( $\mathrm{n}$ $=3)$, Crouzon's disease $(n=3)$, aqueductal stenosis $(n=$ $3)$, posttraumatic brain injury $(\mathrm{n}=3)$, and multiloculated hydrocephalus $(n=1)$. In the preterm infants subgroup, the most common etiology of hydrocephalus was posthemorrhagic $(n=32)$.

During the inclusion period, 79 infants received the first valve and shunt (79 primary implants). Fourteen infants, who were referred from other hospitals and already had shunts, underwent revisions during the inclusion period and received a proGAV shunt system (14 secondary implants). During the inclusion period, 19 children underwent revision(s) of the valve while they were still in their infancy; among those infants, 24 proGAV valves were implanted (additional 24 secondary implants). Therefore, a total of 117 proGAV valves (primary and secondary implants) were implanted in patients during infancy and the survival of the valves was followed. The type of CSF diversion was ventriculoperitoneal for all primary implants; among the secondary implants were 2 ventriculoatrial shunts.

A total of 83 revisions had to be performed in 53 patients, among them 30 revisions in the preterm subgroup. In summary, a total of 176 surgeries (including primary surgeries and revision surgeries) were performed during the entire follow-up period. A revision addressed the nonfunctioning parts of the shunt system (e.g., ventricular catheter, valve, or distal catheter; either alone or in combination). In all cases of infection, the complete shunt system was revised. A total of 19 shunts were revised due to a documented shunt infection (infection rate 10.8\%). The ventricular catheter had to be revised 65 times in 41 children (among them were 21 preterm infants and 19 infections), and the distal catheter had to be revised 28 times in 25 children (among them were 14 preterm infants and 19 infections). Forty-four valve exchanges were necessary in 37 patients; 20 of them were in the preterm subgroup.

A shunt infection was the reason for valve revision in 19 of 44 patients (among them 13 preterm infants) a mean of $3.47 \pm 6.7$ months after implantation. Ten infections occurred within the first month and a total of 16 infections occurred during the first 3 months after implantation. Three of the preterm infants needed 2 valve exchanges each due to recurring infections. In these patients, explantation, externalization, and administration of intravenous antibiotics was performed. However, retrospective analysis showed that the reimplantation of the system was scheduled too early, i.e., before complete CSF clearance of the infection could be reached. Among the 6 infants who were born at full term, there was only 1 recurrent infection.

An occlusion of the proGAV was seen in 14 revisions after a mean of $28 \pm 21.6$ months; among them were 9 children with either a postinfectious or posthemorrhagic hydrocephalus. No patient had more than 1 occlusion of the valve, and the presence of protein clots was seen in all valves. A dysfunction of the valve (i.e., the inability to alter the setting of the valve) was found in 10 cases after a mean of $33 \pm 18.6$ months. In 2 cases, the dysfunction was due to improper use of the DP unit prior to implantation. In those cases, the outer titanium membrane was deformed by immoderate pressure and the blocking mechanism of the rotor was incapacitated. In all other cases, the manufacturer's investigation revealed that protein debris around the rotor was blocking the adjustment mechanism. One valve was exchanged to alter the setting of the gravitational unit (Table 2).

Another reason for an operative revision of a shunt system was impaired wound healing, which occurred in 5 infants ( 2 of them preterm). This resulted in shunt infection in 1 patient, 2 others had further surgeries including ventricular catheter revision and valve occlusion, and 2 cases received only wound revision as additional surgery after shunt implantation.

\section{Shunt and Valve Survival Rates}

The Kaplan-Meier rate of shunt survival of the whole patient cohort was $69 \%$ at 12 months and $34 \%$ at 85 months; for the valve only, the survival rate was $78 \%$ at 12 months and 56\% at 85 months (Fig. 1A, Table 3). In contrast, the corresponding shunt rate for premature infants was $61 \%$ at 12 months and $27 \%$ at 85 months, compared with a $79 \%$ shunt survival rate at 12 months and $46 \%$ at 81 months in full-term infants ( $\mathrm{p}=0.054$; Fig. 1B). The survival rate of the valves in premature infants was $69 \%$ at 12 months and 58\% at 85 months compared with $89 \%$ at 12 months and $53 \%$ at 81 months in full-term infants (p $=0.26$ ). No differences in survival rates were seen when shunt implantation was performed in younger infants (age $\leq 100$ days after the estimated day of delivery) compared with older ones (> 100 days).

However, there was a significant difference if a previous surgery was performed before implantation of a new proGAV system. The survival rates for primary implanted shunts (without previous surgery) at the end of the observation period revealed a shunt survival of $78 \%$ at 12 months and $39 \%$ at 85 months, whereas valve survival was $85 \%$ at 12 months and $59 \%$ at 85 months. This was observed to be significantly better compared with infants with secondary implanted shunts, in whom the implantation of the system was performed as a revision (shunt: $50 \%$ at 12 months and $28 \%$ at 79 months, $\mathrm{p}=0.006$; valve: $63 \%$ at 12 months and $53 \%$ at 79 months, $\mathrm{p}=0.07$; Fig. $1 \mathrm{C}$ and D).

The Kaplan-Meier shunt and valve survival rates of the 2 largest etiological groups of hydrocephalus, posthemorrhagic and in association with a myelomeningocele, were

TABLE 2. Number and sites of surgical revisions

\begin{tabular}{cllcc}
\hline Total No. of Revisions $(\mathrm{n}=83)$ & \multicolumn{1}{c}{ Site of Revision } & No. of Revisions & No. of Children (all/preterm) \\
\hline Combined revisions of: & Ventricular catheter & 65 (infection, 19; other, 46) & $41: 21$ \\
\cline { 2 - 5 } & Distal catheter & 28 (infection, 19; other, 9) & $25: 14$ & $37: 20$ \\
\cline { 2 - 5 } & Valve (proGAV) & 44 (infection, 19; occlusion, 14; dysfunction, 10; other, 1) & $5: 2$ \\
\cline { 2 - 5 } & Wound & 5 & & \\
\hline
\end{tabular}



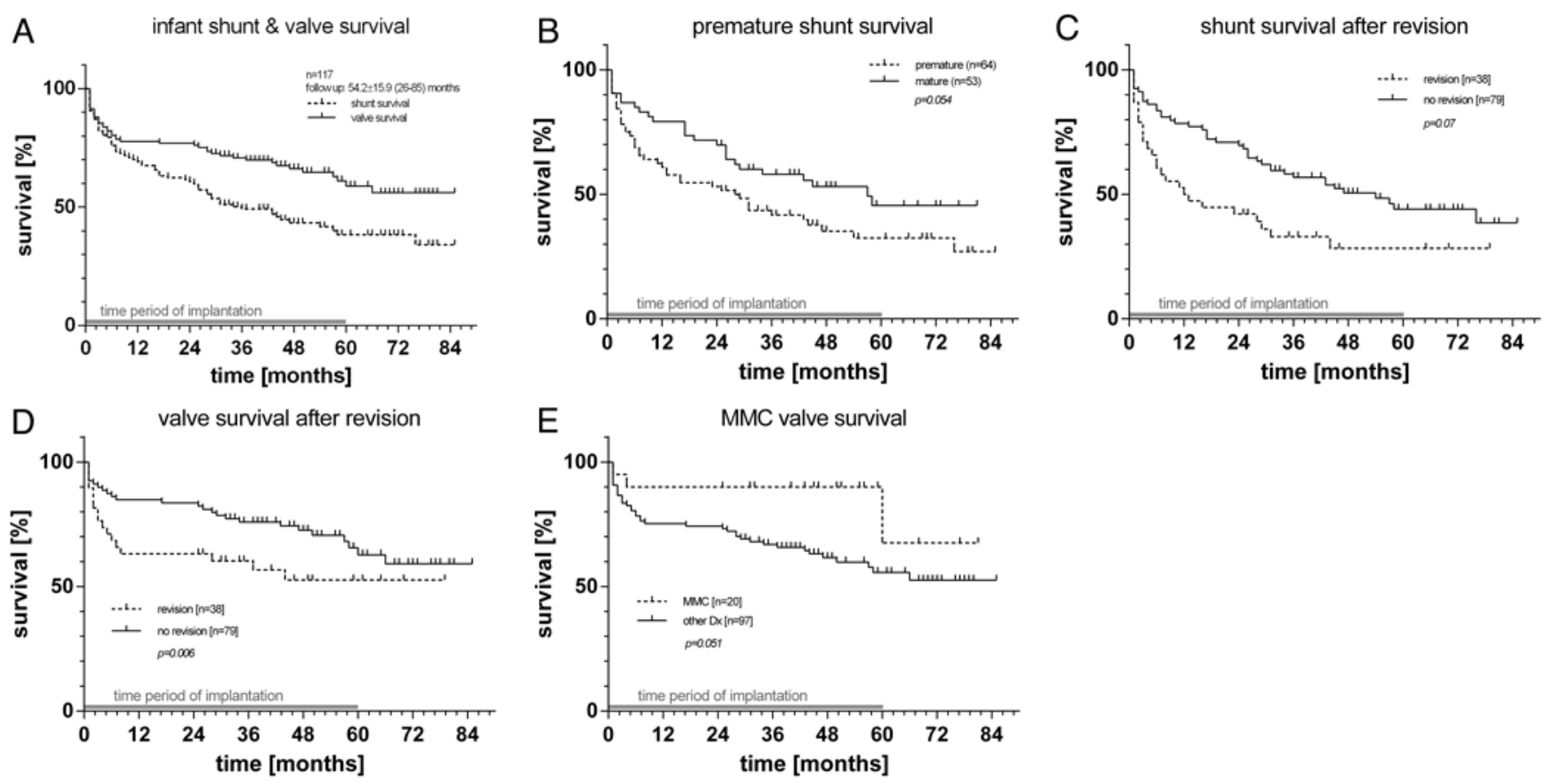

FIG. 1. A: Kaplan-Meier shunt and valve survival curves of the 117 implanted shunt systems for a maximum observation period of 85 months. B: Kaplan-Meier shunt survival curves of the subgroup of premature infants compared with the group of infants born at full term. C and D: Kaplan-Meier survival curves demonstrating an inferior shunt (C) and valve (D) survival rate for revised CSF diversion systems (secondary implants). E: Kaplan-Meier survival curves of the infants with myelomeningocele compared with infants without myelomeningocele. $\mathrm{Dx}=$ diagnosis; $\mathrm{MMC}=$ myelomeningocele.

compared with the rest of the patient cohort. The shunt survival rates among patients with posthemorrhagic hydrocephalus compared with other causes for hydrocephalus were $30 \%$ versus $40 \%(p=0.26)$ and the valve survival rates were $50 \%$ versus $62 \%(\mathrm{p}=0.11)$ at the end of the observation period. The valve survival rates among patients with hydrocephalus in association with a myelomeningocele compared with other causes for hydrocephalus were $68 \%$ versus $53 \%(\mathrm{p}=0.051$; Fig. $1 \mathrm{E})$ at the end of the observation period.

\section{Discussion}

Several studies have shown significant complications in the treatment of infants with hydrocephalus. Possible reasons for this are fragile skin conditions, immature immune response, soft and thin calvarium, and the open fontanelle leading to possible wound-healing problems, CSF collections, shunt infection, involution of the fontanelle, or subdural hygroma. 7,10,12,24,26,33,42,50 Special pediatric implants were designed to be smaller and less voluminous, but these often have fixed low-resistance pressure settings, lack the option to adapt the amount of CSF diversion according to the patient's activity and changing anatomy, and might need later surgical exchange to avoid overdrainage. The new technology of adjustable valves demonstrates the advantage of optionally adapting the drained CSF volume to the individual conditions of the patients, which might be of particular importance in very young infants who will outgrow the pressure setting of a fixed-pressure, lowresistance valve. Antisiphoning devices were introduced to overcome posture-dependent hydrostatic overdrainage.
The proGAV has been used at our institution since 2007 as the standard valve for all children. It provides both the opportunity to respond to changing pathophysiological conditions by adjusting the DP unit and a complementary system to counteract the siphoning effect of the gravitational unit. The valve was introduced in selected pediatric patients before 2007. After promising early results, the standard regimen was changed to include infant patients..$^{18,48} \mathrm{In}$ the present study, we report the shunt and valve survival rates and the reasons for valve exchanges exclusively for the infant cohort. The retrospective investigation of revisions and complication rates in this young patient cohort shows limited shunt and valve survival rates. However, we conclude that implantation of the proGAV is feasible in the infant age group and that implantation of the gravitational unit is tolerated. Its use adds the option of being able to adjust the valve settings early in the therapeutic regimen.

No significant differences were observed in the overall shunt and valve survival rates between patients younger or older than 100 days at the time of implantation. However, the inferior rate of shunt survival in patients who received the proGAV as part of a revision of their shunt system stresses the importance of the necessary optimal primary implantation. Especially within the first year after implantation, a significant loss of implants is observed, which might be influenced by a higher infection rate in this cohort compared with older children. The long-term decrease in the valve survival curve is rather related to obstruction or dysfunction of the valve. This is mostly associated with elevated protein CSF levels that are usually recognized when the valve needs a readjustment, which is not feasible at this stage. 
TABLE 3. Comparisons of shunt and valve survival rates among groups

\begin{tabular}{|c|c|c|c|c|c|c|c|c|c|}
\hline \multirow[b]{2}{*}{ Variable } & \multirow[b]{2}{*}{ No. of Pts } & \multirow[b]{2}{*}{ Type } & \multicolumn{6}{|c|}{$\%$ Survival } & \multirow[b]{2}{*}{ p Value } \\
\hline & & & 12 Mos & 24 Mos & 36 Mos & 48 Mos & 60 Mos & After Max Observation Period (mos) & \\
\hline \multirow[t]{2}{*}{ Total } & 117 & Valve & 78 & 77 & 71 & 66 & 59 & $56(85)$ & NA \\
\hline & & Shunt & 69 & 61 & 49 & 43 & 38 & $34(85)$ & \\
\hline \multirow[t]{2}{*}{ Age $\leq 100$ days } & 57 & Valve & 77 & 77 & 70 & 65 & 56 & $56(81)$ & 0.9 \\
\hline & & Shunt & 72 & 61 & 49 & 39 & 32 & $32(81)$ & 0.52 \\
\hline \multirow[t]{2}{*}{ Age $>100$ days } & 60 & Valve & 78 & 77 & 71 & 67 & 61 & $56(85)$ & \\
\hline & & Shunt & 67 & 60 & 49 & 47 & 44 & $38(85)$ & \\
\hline \multirow[t]{2}{*}{ Premature } & 64 & Valve & 69 & 69 & 64 & 58 & 58 & $58(85)$ & 0.26 \\
\hline & & Shunt & 61 & 53 & 42 & 35 & 32 & $27(85)$ & 0.054 \\
\hline \multirow[t]{2}{*}{ Full term } & 53 & Valve & 89 & 85 & 79 & 77 & 60 & $53(81)$ & \\
\hline & & Shunt & 79 & 70 & 58 & 53 & 46 & $46(81)$ & \\
\hline \multirow[t]{2}{*}{ Secondary implant } & 38 & Valve & 63 & 63 & 60 & 53 & 53 & $53(79)$ & 0.07 \\
\hline & & Shunt & 50 & 42 & 33 & 28 & 28 & $28(79)$ & 0.006 \\
\hline \multirow[t]{2}{*}{ Primary implant } & 79 & Valve & 85 & 84 & 76 & 73 & 63 & $59(85)$ & \\
\hline & & Shunt & 78 & 70 & 57 & 51 & 44 & $39(85)$ & \\
\hline \multirow[t]{2}{*}{$\mathrm{PH}$} & 58 & Valve & 72 & 72 & 60 & 58 & 54 & $50(85)$ & 0.11 \\
\hline & & Shunt & 66 & 57 & 41 & 39 & 36 & $30(85)$ & 0.26 \\
\hline \multirow[t]{2}{*}{ Others } & 59 & Valve & 83 & 81 & 81 & 75 & 62 & $62(81)$ & \\
\hline & & Shunt & 73 & 64 & 57 & 48 & 40 & $40(81)$ & \\
\hline \multirow[t]{2}{*}{ MMC } & 20 & Valve & 90 & 90 & 90 & 90 & 68 & $68(81)$ & 0.051 \\
\hline & & Shunt & 85 & 80 & 62 & 46 & 46 & $46(81)$ & 0.24 \\
\hline \multirow[t]{2}{*}{ Others } & 97 & Valve & 75 & 74 & 67 & 62 & 56 & $53(85)$ & \\
\hline & & Shunt & 66 & 57 & 46 & 42 & 37 & $32(85)$ & \\
\hline
\end{tabular}

Max = maximum $; \mathrm{MMC}=$ myelomeningocele $; \mathrm{NA}=$ not applicable; $\mathrm{PH}=$ posthemorrhagic.

* Versus corresponding group.

Perhaps the most relevant data from the study include the survival rate of primary implants in infants without any previous interventions $(\mathrm{n}=79)$, which was $85 \%$ at 12 months and $59 \%$ at 85 months for the valve and $78 \%$ at 12 months and $39 \%$ at 85 months for the shunt; these data may have the strongest value for comparison with data from the literature. In our previous report, ${ }^{48}$ which examined 237 children with hydrocephalus who had a proGAV implant, 62 infants with a mean follow-up of 21 months (6-38 months) were included. The Kaplan-Meier valve survival rate after 12 months for all children in this study was similar to the present data (valve, $81 \%$ and shunt, $72 \%$ ). This previous study clearly demonstrated the higher risk of shunt failure in infants compared with older children $(\leq 1$ year, $77 \%$ vs $>1$ year, $90.1 \%)$. The importance of a longer follow-up is apparent, because shunt failure becomes increasingly likely with longer follow-up.

Among other studies, Robinson et al. ${ }^{42}$ reported the complication rates in 158 infants with shunts, who received either no valve, a low-pressure valve, or a mediumto high-pressure fixed DP valve (Table 4). With a total of 246 revisions during a follow-up period of 9 years, they reached the study end point with overall shunt survival rates of $52 \%, 48 \%$, and $37 \%$ after 1,2 , and 5 years, respectively. Dividing the subgroups did show a significantly lower survival rate for the no- or low-pressure valve group, especially during the first 6 months after shunt insertion (shunt failure rates: 1 year 58\% and 5 years $72 \%$ with no valve or a low-pressure valve, 1 year $31 \%$ and 5 years $47 \%$ with a medium- or high-pressure valve). Twenty-five revisions were necessary due to overdrainage. The relevant conclusion from this observation is that no- or low-pressure rates might cause major long-term complications due to significant overdrainage, which is mostly compensated for by infants and young children but to a lesser extent by adolescents. The authors concluded that a low valve opening pressure is an important contributing factor for shunt complications.

With a smaller cohort, the results from Weinzierl et al. ${ }^{53}$ underline the necessity to focus on overdrainage-related problems early in childhood. Their cohort included 15 infants $<6$ months old, who were treated with an adjustable Hakim DP valve (Codman) without a siphoncompensating mechanism. The development of slit ventricles as a result of overdrainage, which were observed by ultrasound within the first 12 months, could not be sufficiently prevented by increasing the DP valve from an initial pressure of $10 \mathrm{~cm} \mathrm{H}_{2} \mathrm{O}$ to $15-20 \mathrm{~cm} \mathrm{H}_{2} \mathrm{O}$. Two other available devices were used by Martínez-Lage et al. in an infant cohort. ${ }^{32}$ They implanted the adjustable valve Sophy SM3 as well as the subsequent valve types, SM8 and Polaris (Sophysa), in a cohort of 100 babies (40 preterm and 60 full term; $<2$ months old). In this study, 31 revisions due to proximal obstruction, infection, technical problems, or "miscellaneous" reasons were reported. The death of 1 child was related to shunt malfunction. After a 


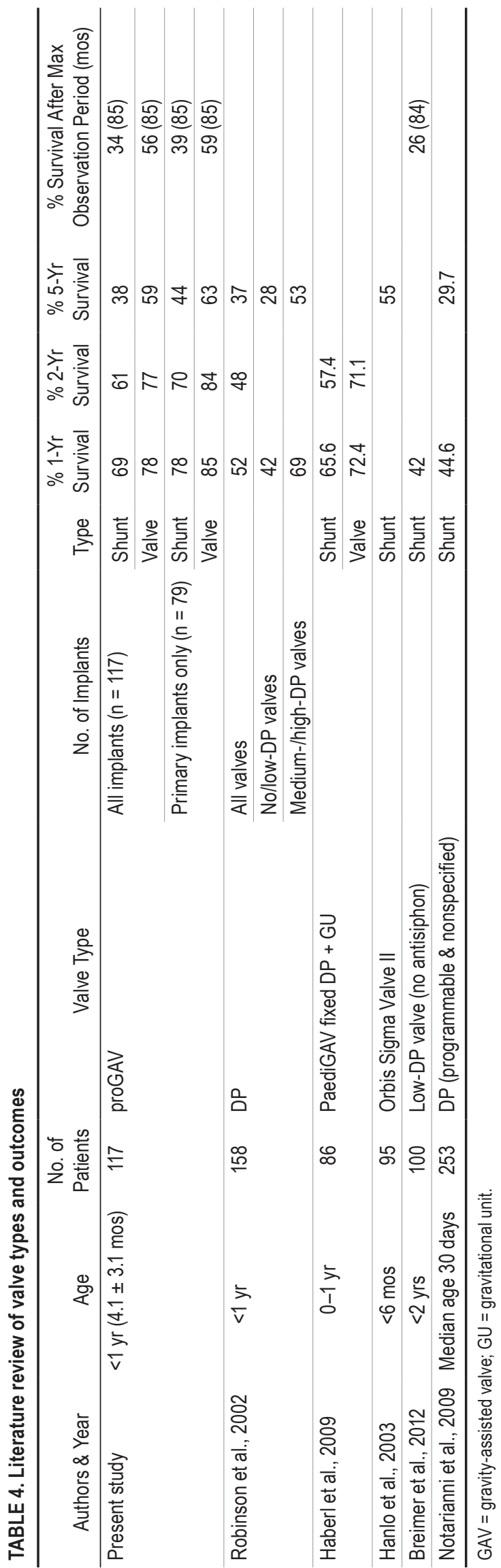

mean follow-up of 55 months, they performed 91 readjustments. Thirty-three of those became necessary after unintentional MRI-related readjustments (Polaris excluded), and $62 \%$ of all patients who underwent MRI needed 1 or more valve pressure resettings. Because we avoid routine CT scanning in children to minimize radiation and use MRI as the routine elective for imaging, we appreciate the advantage of the proGAV or the Polaris valve, which are inert to magnetic field exposure up to 3 T.,3,48-30,34,35

Another aspect is to compare our data with those of nonadjustable, gravity-assisted valves collected in a multicenter prospective study of 169 patients, including 86 infants $\left(<1\right.$ year) who received the paediGAV; ${ }^{20}$ this study reported shunt survival rates of $65.6 \%$ and $57.4 \%$ and valve survival rates of $72.4 \%$ and $71.1 \%$ after 12 and 24 months, respectively. However, the comparison of a single-center retrospective study with a multicenter prospective study is limited. In another multicenter study by Hanlo et al., a population of 557 patients from all age groups underwent implantation of the nonadjustable Orbis-Sigma II valve (Cordis). ${ }^{21}$ A significant difference was observed in the overall shunt survival rate between patients younger than 6 months (55\%) and those who were older than 6 months (63\%). The authors also reported that survival differences in infants occurred within the first few months after surgery, which is consistent with our results and those of other studies in which a failure rate of $48 \%-58 \%$ within the first year is described..$^{8,14,23,36,42,45}$ This is also emphasized by Reinprecht et al., ${ }^{41}$ who reported results from a cohort of 42 preterm infants with posthemorrhagic hydrocephalus and shunt implantation. They noted occlusion of the distal catheter as the primary cause for revision, which occurred mainly during the first few months.

Although our demonstrated survival rates of the implanted proGAV shunt system are comparable to the rates reported in the literature, limitations of our study include its retrospective, single-center setup without a control group. Furthermore, the observation period is still too short to adequately assess signs and symptoms of chronic overdrainage and to answer the question of whether a gravitational unit with a resistance of $20 \mathrm{~cm} \mathrm{H}_{2} \mathrm{O}$ is enough for long-term follow-up. Nevertheless, the feasibility of using this shunt system in an infant population is demonstrated, which has similarly been shown for a general pediatric population. ${ }^{20,43,48}$ The use of the gravitational unit of the system to try to counteract severe overdrainage is also well tolerated by infants. Clinical observation has shown that during long-term follow-up, signs and symptoms of overdrainage (e.g., decreased ventricular size on imaging, diminished development of head circumference, and headaches) may develop with the advancing growth and activity of the child. Therefore, the adjustability of the DP unit of proGAV is important because it adds the option to gradually increase the resistance of the shunt system. ${ }^{18}$

To generally improve shunt survival in infants, therapeutic approaches are needed. These include the strict protocol to avoid shunt infections and, possibly, surgical approaches to decrease CSF protein concentration before shunt implantation. In this regard, we have recently introduced neuroendoscopic lavage of the ventricular system, which our institution routinely uses for intraventricular 
hemorrhage and postinfectious conditions. For this study, however, it has a limited impact because only 5 infants with posthemorrhagic and 2 infants with postinfectious hydrocephalus who were receiving neuroendoscopic lavage were included. The outcome data of this approach are currently being evaluated to quantify survival rates with this enhanced protocol. A further challenge will be to investigate the long-term neurofunctional outcome in these infant patients to prove that counteracting chronic overdrainage is beneficial.

\section{Conclusions}

Hydrocephalus in infants represents a special cohort of patients in whom avoiding shunt complications remains challenging. The survival rates of the proGAV system, which is used routinely in our institution for all children, demonstrate good applicability of this system in this age group, but do not show much difference compared with other studies and other valve systems as published in the literature. The gravitational unit with a pressure setting of $20 \mathrm{~cm} \mathrm{H}_{2} \mathrm{O}$ is well tolerated by all infants without showing symptoms of underdrainage and may avoid problems of overdrainage from early in treatment. Whether this will apply for much longer durations of follow-up cannot be answered by this study. The adjustable DP unit aims to apply flexibility in a cohort of patients for whom the optimal opening pressure is hard to predict. The rationale is that the initial use of a sophisticated technology for infants with hydrocephalus might achieve long-term quality of care. Further studies are necessary to prove the benefit of this approach and to collect data on neurofunctional outcome.

\section{References}

1. Abbott R, Epstein FJ, Wisoff JH: Chronic headache associated with a functioning shunt: usefulness of pressure monitoring. Neurosurgery 28:72-77, 1991

2. Ahn ES, Bookland M, Carson BS, Weingart JD, Jallo GI: The Strata programmable valve for shunt-dependent hydrocephalus: the pediatric experience at a single institution. Childs Nerv Syst 23:297-303, 2007

3. Akbar M, Stippich C, Aschoff A: Magnetic resonance imaging and cerebrospinal fluid shunt valves. N Engl J Med 353:1413-1414, 2005

4. Allin DM, Czosnyka M, Richards HK, Pickard JD, Czosnyka $\mathrm{ZH}$ : Investigation of the hydrodynamic properties of a new MRI-resistant programmable hydrocephalus shunt. Cerebrospinal Fluid Res 5:8, 2008

5. Aschoff A, Kremer P, Benesch C, Fruh K, Klank A, Kunze S: Overdrainage and shunt technology. A critical comparison of programmable, hydrostatic and variable-resistance valves and flow-reducing devices. Childs Nerv Syst 11:193-202, 1995

6. Aschoff A, Kremer P, Hashemi B, Kunze S: The scientific history of hydrocephalus and its treatment. Neurosurg Rev 22:67-95, 1999

7. Badiane SB, Sakho Y, Kabre A, Ba MC, Gueye EM, Kone S, et al: [Non-infectious complications of treatment of hydrocephalus by shunt.] Dakar Méd 37:15-19, 1992

8. Breimer GE, Sival DA, Hoving EW: Low-pressure valves in hydrocephalic children: a retrospective analysis. Childs Nerv Syst 28:469-473, 2012

9. Browd SR, Gottfried ON, Ragel BT, Kestle JR: Failure of cerebrospinal fluid shunts: part II: overdrainage, loculation, and abdominal complications. Pediatr Neurol 34:171-176, 2006

10. Choux M, Genitori L, Lang D, Lena G: Shunt implantation: reducing the incidence of shunt infection. J Neurosurg 77:875-880, 1992

11. Czosnyka Z, Czosnyka M, Richards HK, Pickard JD: Posture-related overdrainage: comparison of the performance of 10 hydrocephalus shunts in vitro. Neurosurgery 42:327-334, 1998

12. Drake JM, Kestle JT: Determining the best cerebrospinal fluid shunt valve design: the pediatric valve design trial. Neurosurgery 43:1259-1260, 1998

13. Drake JM, Kestle J: Rationale and methodology of the multicenter pediatric cerebrospinal fluid shunt design trial. Childs Nerv Syst 12:434-447, 1996

14. Drake JM, Kestle JR, Milner R, Cinalli G, Boop F, Piatt J Jr, et al: Randomized trial of cerebrospinal fluid shunt valve design in pediatric hydrocephalus. Neurosurgery 43:294-305, 1998

15. Drake JM, Sainte-Rose C: The shunt book. Cambridge, MA: Blackwell Science, 1995

16. Faulhauer K, Schmitz P: Overdrainage phenomena in shunt treated hydrocephalus. Acta Neurochir (Wien) 45:89-101, 1978

17. Gangemi M, Maiuri F, Colella G, Magro F, Seneca V, de Divitiis $\mathrm{E}$ : Is endoscopic third ventriculostomy an internal shunt alone? Minim Invasive Neurosurg 50:47-50, 2007

18. Gebert AF, Schulz M, Haberl H, Thomale UW: Adjustments in gravitational valves for the treatment of childhood hydrocephalus-a retrospective survey. Childs Nerv Syst 29:2019-2025, 2013

19. Gruber R, Jenny P, Herzog B: Experiences with the anti-siphon device (ASD) in shunt therapy of pediatric hydrocephalus. J Neurosurg 61:156-162, 1984

20. Haberl EJ, Messing-Juenger M, Schuhmann M, Eymann R, Cedzich C, Fritsch MJ, et al: Experiences with a gravityassisted valve in hydrocephalic children. Clinical article. J Neurosurg Pediatr 4:289-294, 2009

21. Hanlo PW, Cinalli G, Vandertop WP, Faber JA, Bøgeskov L, Børgesen SE, et al: Treatment of hydrocephalus determined by the European Orbis Sigma Valve II survey: a multicenter prospective 5-year shunt survival study in children and adults in whom a flow-regulating shunt was used. J Neurosurg 99:52-57, 2003

22. Horton D, Pollay M: Fluid flow performance of a new siphon-control device for ventricular shunts. J Neurosurg 72:926-932, 1990

23. Jain H, Sgouros S, Walsh AR, Hockley AD: The treatment of infantile hydrocephalus: "differential-pressure" or "flowcontrol" valves. A pilot study. Childs Nerv Syst 16:242-246, 2000

24. Kang JK, Lee IW: Long-term follow-up of shunting therapy. Childs Nerv Syst 15:711-717, 1999

25. Khan RA, Narasimhan KL, Tewari MK, Saxena AK: Role of shunts with antisiphon device in treatment of pediatric hydrocephalus. Clin Neurol Neurosurg 112:687-690, 2010

26. Korinth MC, Weinzierl MR, Gilsbach JM: Experience with a new concept to lower non-infectious complications in infants with programmable shunts. Eur J Pediatr Surg 13:81-86, 2003

27. Kulkarni AV, Drake JM, Kestle JR, Mallucci CL, Sgouros S, Constantini S: Endoscopic third ventriculostomy vs cerebrospinal fluid shunt in the treatment of hydrocephalus in children: a propensity score-adjusted analysis. Neurosurgery 67:588-593, 2010

28. Lavinio A, Harding S, Van Der Boogaard F, Czosnyka M, Smielewski P, Richards HK, et al: Magnetic field interactions in adjustable hydrocephalus shunts. J Neurosurg Pediatr 2:222-228, 2008 
29. Lefranc M, Ko JY, Peltier J, Fichten A, Desenclos C, Macron $\mathrm{JM}$, et al: Effect of transcranial magnetic stimulation on four types of pressure-programmable valves. Acta Neurochir (Wien) 152:689-697, 2010

30. Lindner D, Preul C, Trantakis C, Moeller H, Meixensberger $\mathrm{J}$ : Effect of 3T MRI on the function of shunt valves-evaluation of Paedi GAV, Dual Switch and proGAV. Eur J Radiol 56:56-59, 2005

31. Liniger P, Marchand S, Kaiser GL: Flow control versus antisiphon valves: late results concerning slit ventricles and slitventricle syndrome. Eur J Pediatr Surg 13 (Suppl 1):S3S6, 2003

32. Martínez-Lage JF, Almagro MJ, Del Rincón IS, Pérez-Espejo MA, Piqueras C, Alfaro R, et al: Management of neonatal hydrocephalus: feasibility of use and safety of two programmable (Sophy and Polaris) valves. Childs Nerv Syst 24:549_ 556, 2008

33. Mottolese C, Grando J, Convert J, Abdoulrahman M, Lelievre H, Vandenesch F, et al: Zero rate of shunt infection in the first postoperative year in children-dream or reality? Childs Nerv Syst 16:210-212, 2000

34. Nakashima K, Nakajo T, Kawamo M, Kato A, Ishigaki S, Murakami H, et al: Programmable shunt valves: in vitro assessment of safety of the magnetic field generated by a portable game machine. Neurol Med Chir (Tokyo) 51:635-638, 2011

35. Nakashima K, Oishi A, Itokawa H, Fujimoto M: [Effect of magnetic fields from home-use magnetic induction therapy apparatuses on adjustable cerebrospinal fluid shunt valves.] No Shinkei Geka 38:725-729, 2010 (Jpn)

36. Notarianni C, Vannemreddy P, Caldito G, Bollam P, Wylen E, Willis B, et al: Congenital hydrocephalus and ventriculoperitoneal shunts: influence of etiology and programmable shunts on revisions. J Neurosurg Pediatr 4:547-552, 2009

37. Oi S, Matsumoto S: Hydrocephalus in premature infants. Characteristics and therapeutic problems. Childs Nerv Syst 5:76-82, 1989

38. Oi S, Matsumoto S: Infantile hydrocephalus and the slit ventricle syndrome in early infancy. Childs Nerv Syst 3:145150, 1987

39. Pollack IF, Albright AL, Adelson PD: A randomized, controlled study of a programmable shunt valve versus a conventional valve for patients with hydrocephalus. Neurosurgery 45:1399-1411, 1999

40. Pudenz RH, Foltz EL: Hydrocephalus: overdrainage by ventricular shunts. A review and recommendations. Surg Neurol 35:200-212, 1991

41. Reinprecht A, Dietrich W, Berger A, Bavinzski G, Weninger M, Czech T: Posthemorrhagic hydrocephalus in preterm infants: long-term follow-up and shunt-related complications. Childs Nerv Syst 17:663-669, 2001

42. Robinson S, Kaufman BA, Park TS: Outcome analysis of initial neonatal shunts: does the valve make a difference? Pediatr Neurosurg 37:287-294, 2002

43. Rohde V, Haberl EJ, Ludwig H, Thomale UW: First experiences with an adjustable gravitational valve in childhood hydrocephalus. J Neurosurg Pediatr 3:90-93, 2009

44. Rohde V, Mayfrank L, Ramakers VT, Gilsbach JM: Four- year experience with the routine use of the programmable Hakim valve in the management of children with hydrocephalus. Acta Neurochir (Wien) 140:1127-1134, 1998

45. Sainte-Rose C, Hooven MD, Hirsch JF: A new approach in the treatment of hydrocephalus. J Neurosurg 66:213-226, 1987

46. Sprung C, Miethke C, Trost HA, Lanksch WR, Stolke D: The dual-switch valve. A new hydrostatic valve for the treatment of hydrocephalus. Childs Nerv Syst 12:573-581, 1996

47. Stellman-Ward GR, Bannister CM, Lewis MA, Shaw J: The incidence of chronic headache in children with shunted hydrocephalus. Eur J Pediatr Surg 7 (Suppl 1):12-14, 1997

48. Thomale UW, Gebert AF, Haberl H, Schulz M: Shunt survival rates by using the adjustable differential pressure valve combined with a gravitational unit (proGAV) in pediatric neurosurgery. Childs Nerv Syst 29:425-431, 2013

49. Tian AG, Hintz SR, Cohen RS, Edwards MS: Ventricular access devices are safe and effective in the treatment of posthemorrhagic ventricular dilatation prior to shunt placement. Pediatr Neurosurg 48:13-20, 2012

50. Tuli S, Drake J, Lawless J, Wigg M, Lamberti-Pasculli M: Risk factors for repeated cerebrospinal shunt failures in pediatric patients with hydrocephalus. J Neurosurg 92:31-38, 2000

51. Warf BC, Bhai S, Kulkarni AV, Mugamba J: Shunt survival after failed endoscopic treatment of hydrocephalus. J Neurosurg Pediatr 10:463-470, 2012

52. Weinzierl MR, Hans FJ, Stoffel M, Oertel MF, Korinth MC: Experience with a gravitational valve in the management of symptomatic overdrainage in children with shunts. J Neurosurg Pediatr 9:468-472, 2012

53. Weinzierl MR, Rohde V, Gilsbach JM, Korinth M: Management of hydrocephalus in infants by using shunts with adjustable valves. J Neurosurg Pediatr 2:14-18, 2008

54. Zemack G, Romner B: Seven years of clinical experience with the programmable Codman Hakim valve: a retrospective study of 583 patients. J Neurosurg 92:941-948, 2000

\section{Disclosures}

Dr. Thomale has been a consultant for Aesculap and received travel funds and a lecture honorarium. Dr. Schulz received a onetime lecture fund from MIETHKE/Aesculap.

\section{Author Contributions}

Conception and design: Thomale, Gebert, Schulz. Acquisition of data: all authors. Analysis and interpretation of data: all authors. Drafting the article: Gebert, Schulz. Critically revising the article: Thomale, Schulz, Schwarz. Reviewed submitted version of manuscript: Thomale, Schulz. Statistical analysis: Thomale, Gebert, Schulz. Study supervision: Thomale.

\section{Correspondence}

Ulrich-Wilhelm Thomale, Pediatric Neurosurgery, Charité University Hospital, Berlin, Campus Virchow Klinikum, Augustenburger Platz 1, Berlin 13353, Germany. email: uthomale@ charite. de. 